\title{
Supplementary For: Digital Microfluidics Chips for Execution and Real-Time Monitoring of Multiple Ribozymatic Cleavage Reactions
}

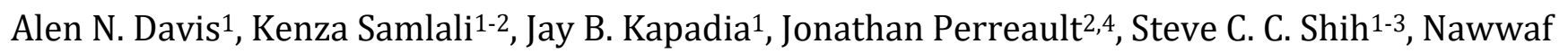
Kharma1-2*

${ }^{1}$ Department of Electrical and Computer Engineering, Concordia University, Montreal, Québec, H3G 1M8, Canada

${ }^{2}$ Centre for Applied Synthetic Biology, Concordia University, Montréal, H4B 1R6, Québec, Canada

3 Department of Biology, Concordia University, Montréal, H4B 1R6, Québec, Canada

${ }^{4}$ Armand-Frappier Health Biotechnology Center, Institut national de la recherche scientifique, Laval, Québec, H7V 1B7, Canada

${ }^{*}$ Corresponding Author.

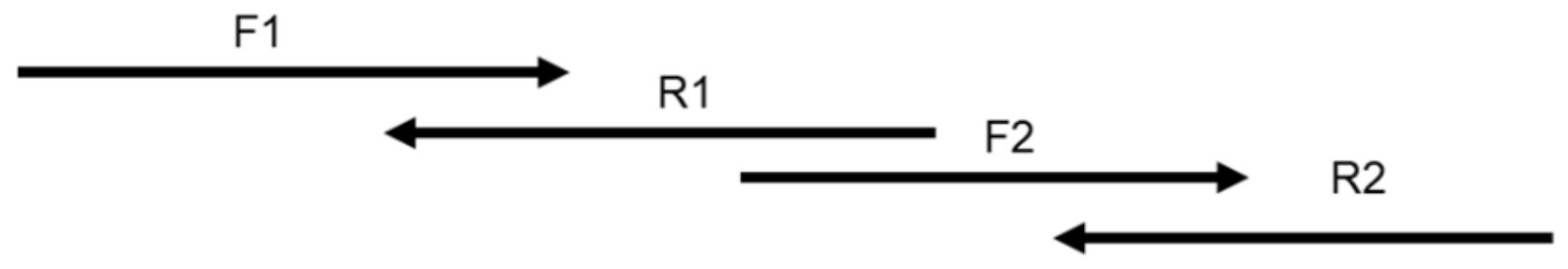

Figure S1: Schematic representation of primerize assembly design. 
(A)

$+$

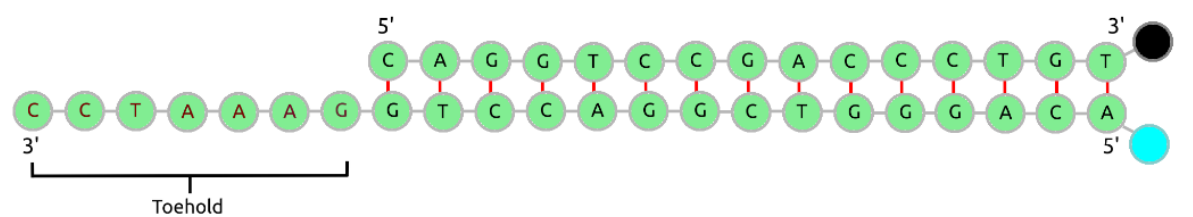

Figure S2: Preparation of the quenched probe. (A) A single-stranded DNA (ssDNA) with a Cy5 fluorophore linked to its 5 '-end (named F-strand). (B) An ssDNA with a black hole quencher (BHQ-3) attached to its 3'-end (Q-strand). A mixture of F-strand (0. $5 \mu \mathrm{M})$ and Q-strand $(0.6 \mu \mathrm{M})$ in the cleavage-buffer yields a quenched probe $(\mathrm{C})$ after thermal cycling $\left(3 \mathrm{~min}\right.$ denaturation at $95{ }^{\circ} \mathrm{C}, 15 \mathrm{~min}$ annealing at $50^{\circ} \mathrm{C}$, and annealing at $37^{\circ} \mathrm{C}$ for 15 minutes). The quenched probe has seven unbounded bases (indicated in red) at the $3^{\prime}$ end of the bottom strand forming a toehold. When the probe is mixed with a strand (ssDNA or RNA) complementary to the Fstrand, the toehold facilitates a stronger binding between the newly added strand and F-strand. This displaces the quencher from the probe and allowing it to fluoresce.

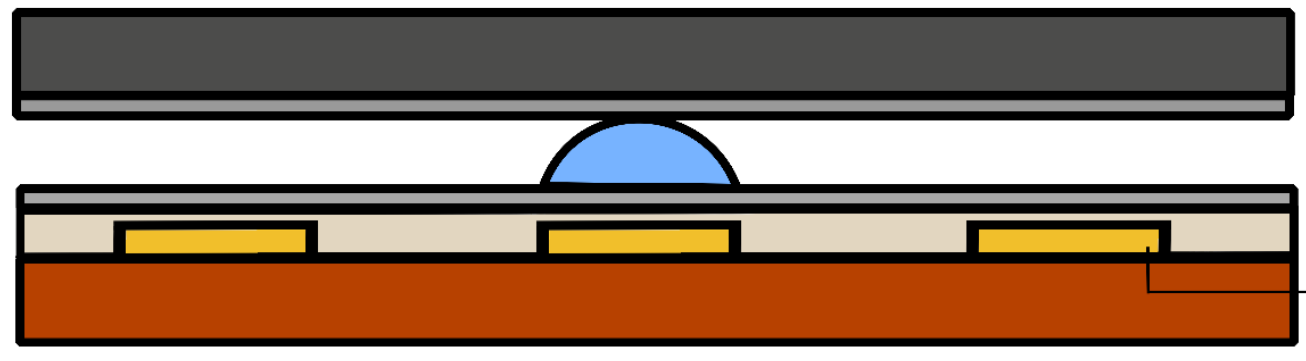

$\rightarrow$ Top Plate (ITO)

Figure S3: Side view of the digital microfluidic device. The DMF device is composed of a glass substrate with chromium electrodes imprinted on it. The chip is given a layer of dielectric coating (parylene) and a hydrophobic coating (Teflon-AF). Droplet on the setup is sandwiched between the DMF device and a top plate of ITO (also coated with Teflon-AF). 


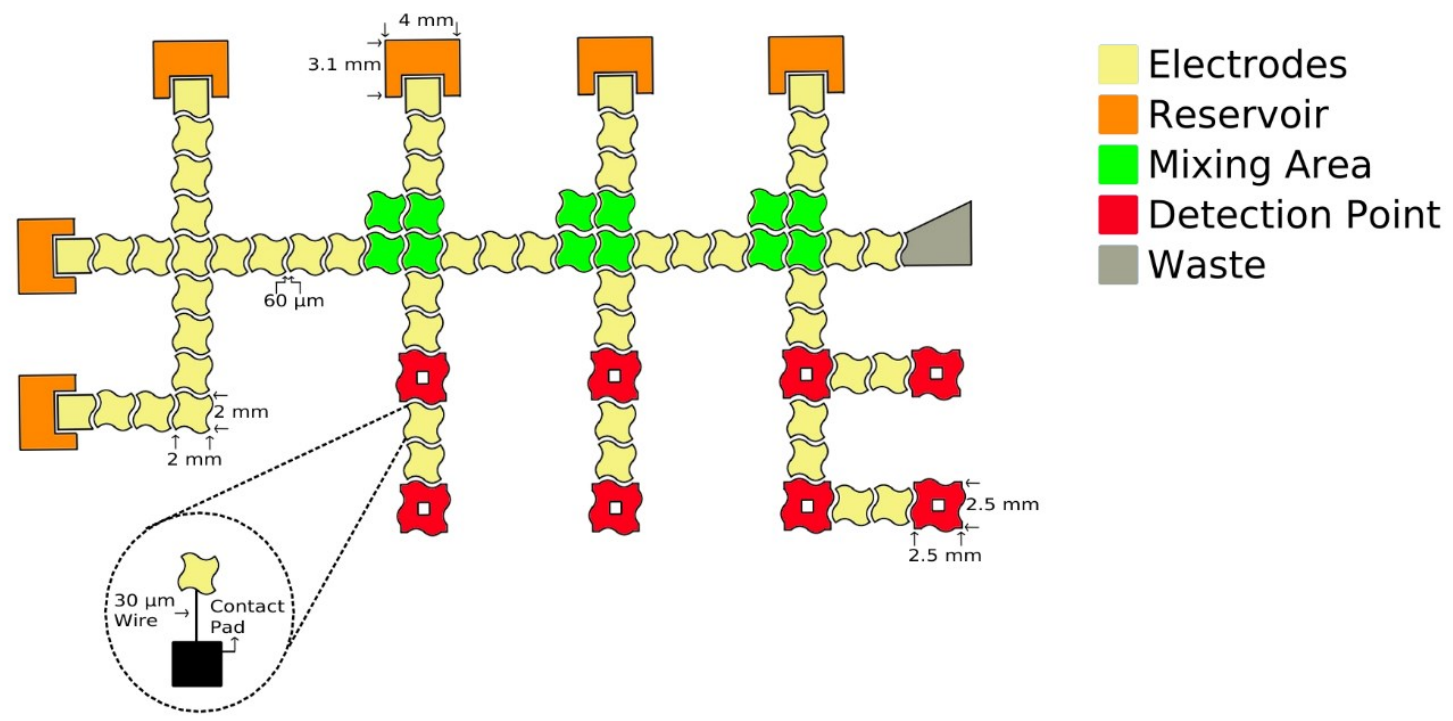

Figure S4: A schematic of the DMF chip and device operations to perform the ribozyme cleavage assay. The design consists of 64 electrodes ( $2 \times 2 \mathrm{~mm}^{2}$ each), 6 reservoirs ( $4 \times 3.1 \mathrm{~mm}^{2}$ each), 3 mixing areas (composed of 4 electrodes each) and 8 detection points $\left(2.5 \times 2.5 \mathrm{~mm}^{2}\right.$ each). The inter-electrode spacing in the design is maintained $60 \mu \mathrm{m}$. The electrodes are connected to contact pads using connecting wires of thickness $30 \mu \mathrm{m}$.

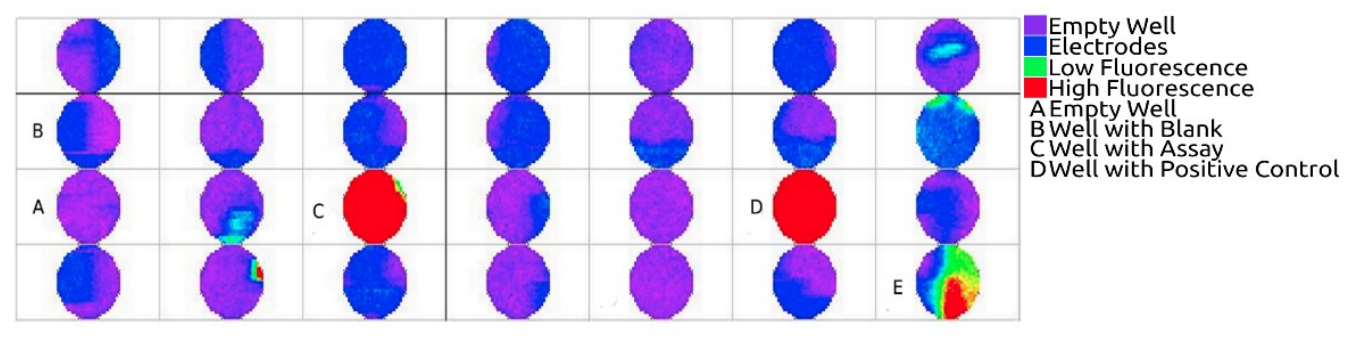

(A)

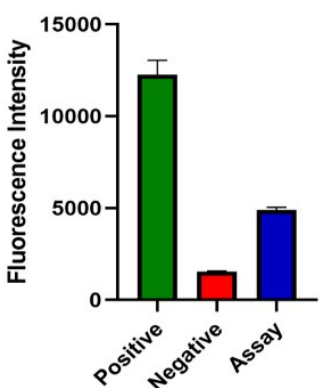

(B)

Figure S5: On-chip fluorescence intensity measurements. (A) A well-scan of the DMF device after carrying out a ribozymatic experiment (chip is scanned after $180 \mathrm{mins}$ ). The droplets of the ribozyme cleavage assay and positive control (a strand displacement reaction) exhibit high fluorescence, whereas the negative control (a quenched probe) displays a low fluorescence. (B) A plot of the highest fluorescence intensities at the detection points corresponding to each $\operatorname{droplet}\left(\mathrm{n}=3, \sigma_{\mathrm{Positive}}=470, \sigma_{\mathrm{Negative}}=30\right.$, and $\sigma_{\mathrm{Ass}}=$ 178). 


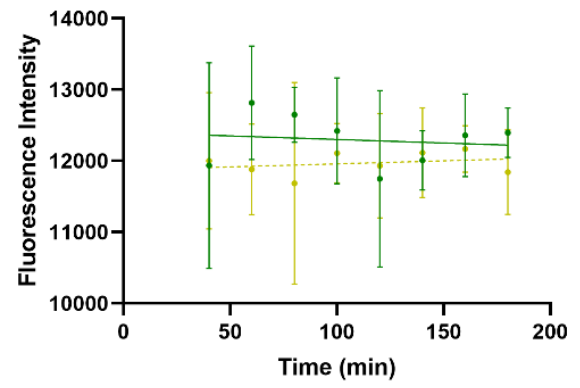

(A) $\rightarrow$ Well-Plate PC

DMF Chip PC

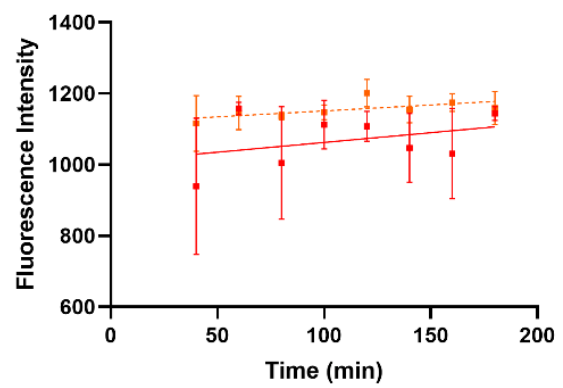

(B)

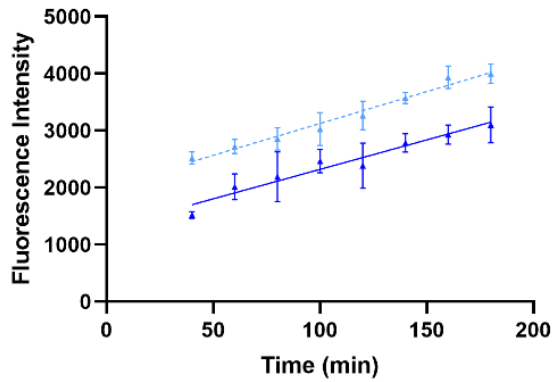

× Well-Plate RZ

DMF Chip RZ

Figure S6: Analysis of change in fluorescence intensities in the ribozyme cleavage experiment. The ribozymatic assay (AS) with one positive control (PC, a strand displacement reaction) and negative control (NC, a quenched probe) is carried both on a DMF chip and well-plate. The fluorescence intensities are read every $20 \mathrm{~min}$ and were plotted against time. A straight line is fit to the readings between $40 \mathrm{~min}$ and $180 \mathrm{~min}$ (linear region) using linear regression to analyze the change in fluorescence over time. The slopes of the lines indicated the change in fluorescence as time progressed. (A) The lines fit to the positive controls exhibit a low slope indicating no or minimal increase in fluorescence both on the chip and well-plate. (B) The negative controls on both platforms display a negligible change in the fluorescence intensities as indicated by the lines with a low value of slopes. (C) The lines fit to the readings from the on-chip, and benchtop assays are steeper indicating an increase in fluorescence intensities due to the cleavage of the ribozyme over time. 

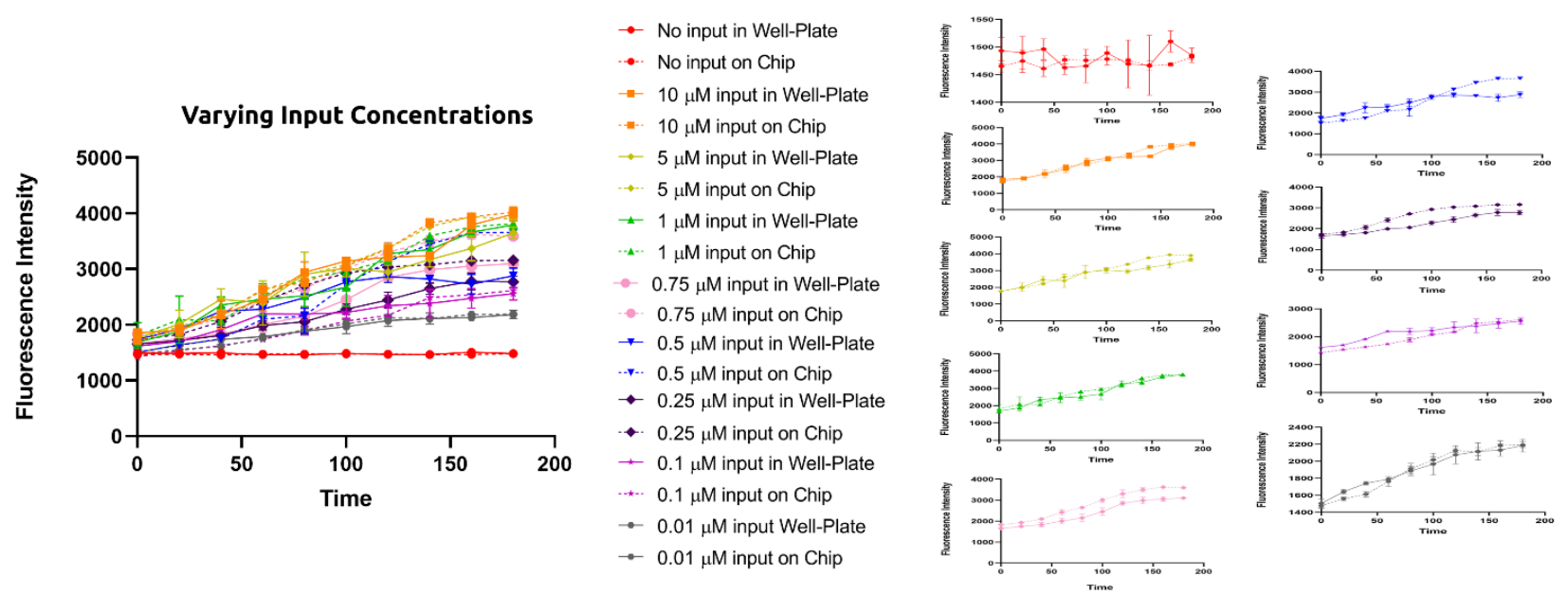

Figure S7: Progress of ribozyme cleavage reaction at different input ssDNA concentrations. The experiment is carried out both on the well-plate and chip with eight different input concentration $(0.01 \mu \mathrm{M}, 0.1 \mu \mathrm{M}, 0.25 \mu \mathrm{M}, 0.5 \mu \mathrm{M}, 0.75 \mu \mathrm{M}, 1 \mu \mathrm{M}, 5 \mu \mathrm{M}, 10 \mu \mathrm{M})$ and on without any input ssDNA. The fluorescence intensities of the assays are regularly read every 20 min and plotted against time. On the right, trends in fluorescence intensities over time for each assay on the chip and well-plate are compared $\left(\mathrm{n}=3, \sigma_{\mathrm{DMF}}{ }^{\mathrm{No}}\right.$ Input $=4$, $\sigma_{\text {Well-Plate }}{ }^{\text {No Input }}=13, \sigma_{\text {DMF }^{10}}=76, \sigma_{\text {Well-Plate }}{ }^{10}=132, \sigma_{\text {DMF }^{5}}=41, \sigma_{\text {Well-Plate }^{5}}=105, \sigma_{\text {DMF }^{1}}=24, \sigma_{\text {Well-Plate }^{1}}=590, \sigma_{\text {DMF }}{ }^{0.75}=64, \sigma_{\text {Well-Plate }}{ }^{0.75}=$

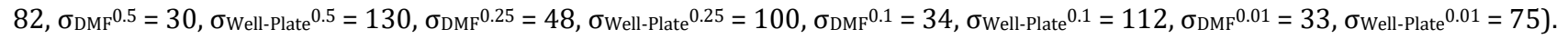

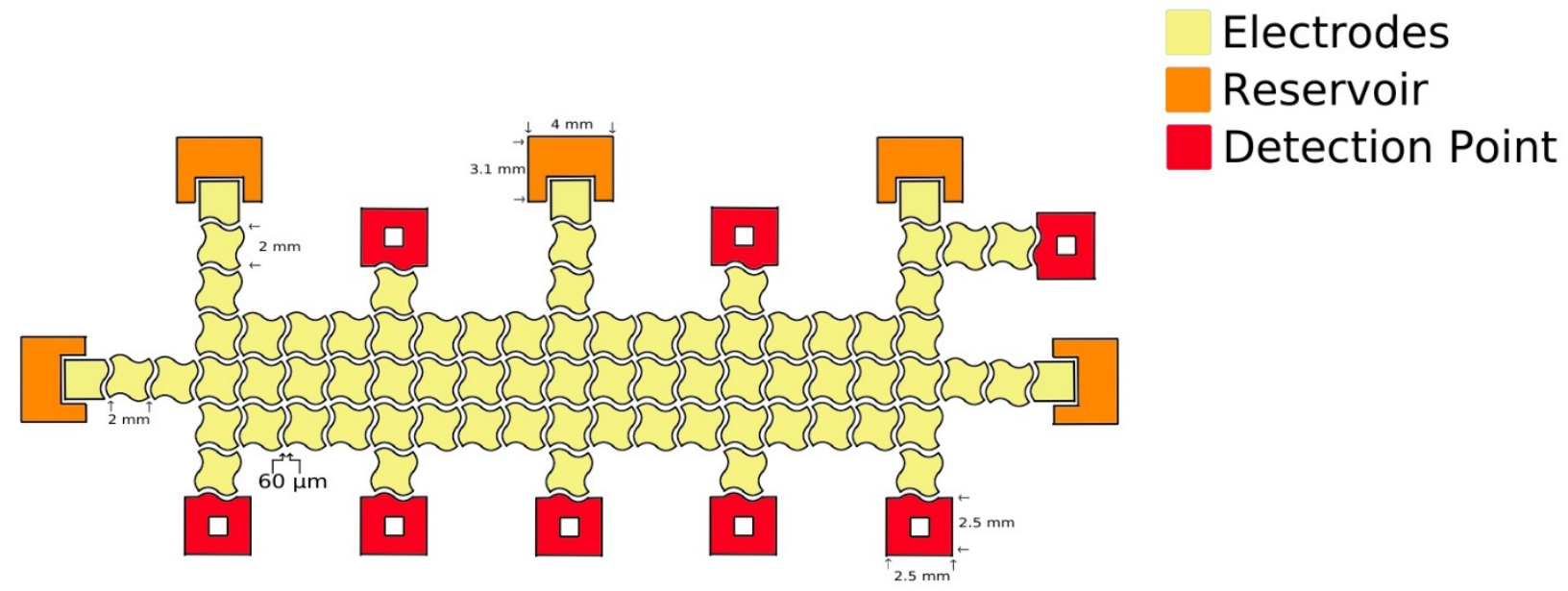

Figure S8: A schematic of a new DMF chip design to carryout multiple experiments. The chip is comprised of eight detection points $\left(2.5 \times 2.5 \mathrm{~mm}^{2}\right.$ ), six reservoirs (each of $4 \times 3.1 \mathrm{~mm}^{2}$ ) and a $3 \times 17$ matrix of electrodes (each of $2 \times 2 \mathrm{~mm}^{2}$ ) for splitting, mixing and merging of droplets. In the design, the spacing between the electrode was $60 \mu \mathrm{m}$. 


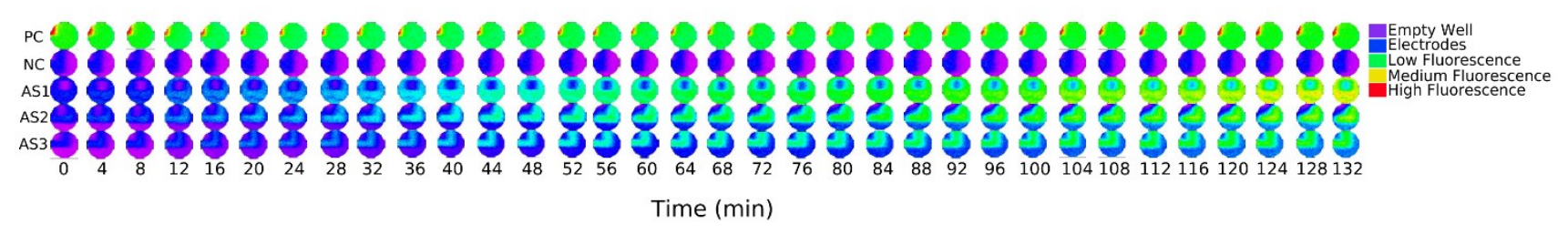

Figure S9: Ribozymatic assay in triplicates on a DMF chip. A ribozymatic assay ( $0.5 \mu \mathrm{M}$ of ribozyme) is carried out on a chip in triplicates (AS1, AS2, AS3) with one positive (PC, a strand displacement reaction) and negative controls (NC, a quenched probe). After carrying out the experiments, the chip was scanned regularly in plate reading every 4 min for 132 min from the start of the experiment. The screenshots of well-scans corresponding to each assayed droplet on the DMF chip are recorded for all the readings. The positive control exhibited a high fluorescence throughout the experiment. At the same time, the negative control had a very low fluorescence intensity. However, all three assays displayed an increase in fluorescence after 20 min and reached a peak at the end of $132 \mathrm{~min}$.

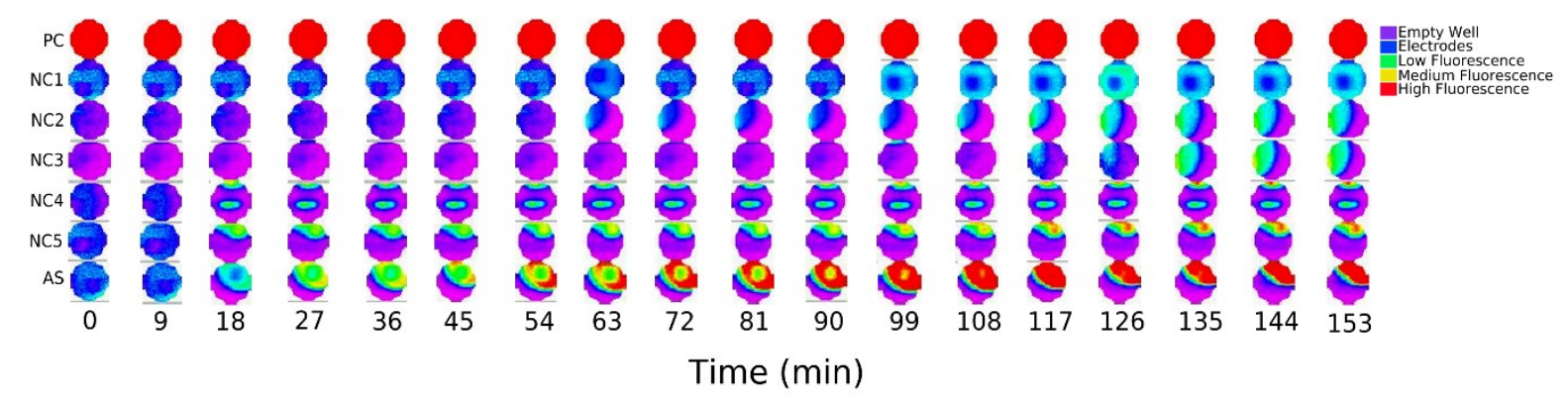

Figure S10: Multiple experiments performed simultaneously on a DMF chip. The figure depicts well-scans of the DMF chip after carrying out a ribozyme cleavage reaction with one positive and five negative controls. The discs represent well-scans of the detection points taken every $9 \mathrm{~min}$ from the start of the experiment using a plate reader. The scans are arranged in rows and columns. Row corresponds to well-scans of a reaction throughout the experiment. Column depicts the scan of all the detection points at a specific time point. The reactions performed on the chip include ribozyme $(0.5 \mu \mathrm{M})$ cleavage assay (AS), a strand displacement reaction as the positive control (PC), cleavage-buffer (NC1), cleavage-buffer with ribozyme (NC2), cleavage-buffer with ribozyme and input strand (NC3), cleavage-buffer with ribozyme and $\mathrm{Mg}^{+2}$ ions (NC4) and cleavage-buffer containing ribozyme, $\mathrm{Mg}^{+2}$ ions and mutated input strand (NC5). The positive control displays the highest level of fluorescence during the experimentation. All the negative controls except NC1 display a slight increase in fluorescence which could be due to the presence of inactive ribozyme in the solution, whereas NC1 exhibits a low level of fluorescence. However, the assay (AS) displays an increase in fluorescence intensities from $18 \mathrm{~min}$ and reached high values after $99 \mathrm{~min}$, which indicated the cleavage of ribozyme as time progressed. 
Time(min) 이 요욕육요

\section{Full length (94 nt)}

Cleaved (72 nt)

\section{Cleaved (22 nt)}

Figure S11. Gel analysis of ribozyme cleavage in the presence of input ssDNA oligonucleotide (10 $\mu \mathrm{M})$. The kinetics were followed for 180 minutes over 30 minutes time points (left to right). 
Standard Curve

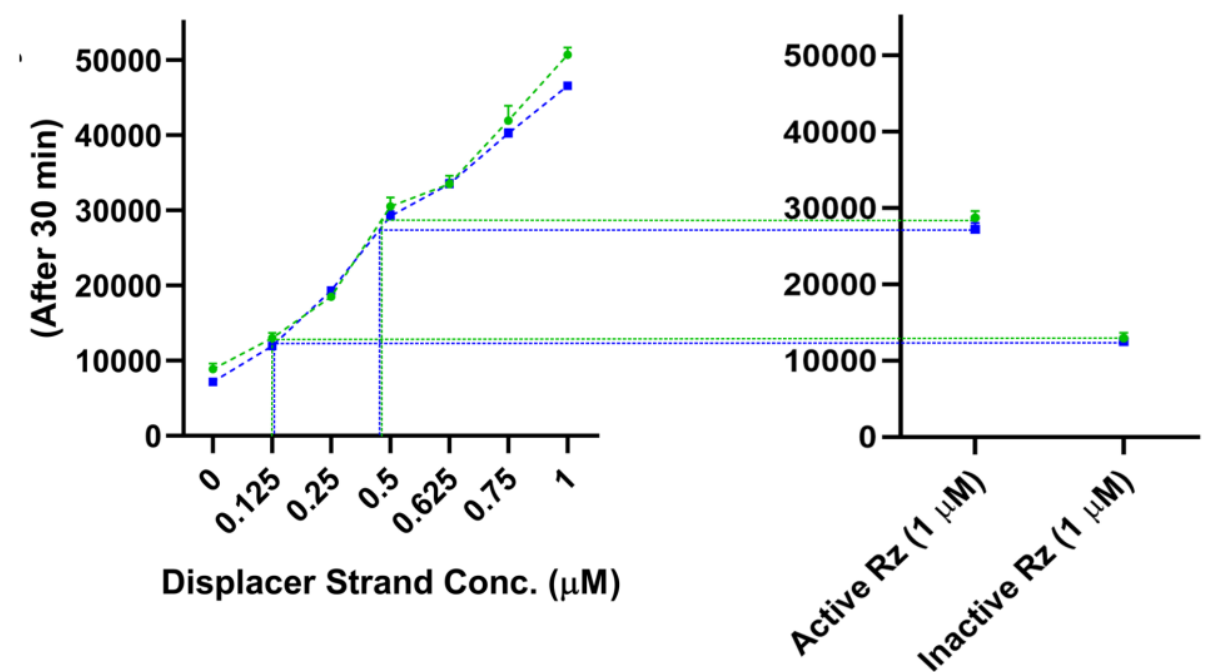

\section{Manganese Activated Rz}

- Well-Plate

- DMF Chip

Figure S12: Quantifying the amount of cleaved-off strand that leaves the manganese activated ribozyme. An experiment using the $\mathrm{Mn}^{2+}$ activated ribozyme $(1 \mu \mathrm{M})$ was performed both on the DMF chip and well-plate, and the fluorescence reading was taken after $30 \mathrm{~min}$ (figure on the right) $\left(\mathrm{n}=3, \sigma_{\mathrm{DMF}}=810\right.$, $\left.\sigma_{\text {Well-Plate }}=870\right)$. Similarly, another experiment with varying ssDNA (same as the cleavedoff strand) concentration was performed on both platforms and fluorescence was measured after 30 min (figure on the left) to get a standard curve $(n=3)$. Both experiments used the same amount of the quenched probe $(1 \mu \mathrm{M})$. The fluorescence caused due to the inactive ribozyme (without $\mathrm{Mn}^{2+}$ ) indicates the amount of noise within the results. After removing the noise, it was observed that the $\sim 30$ ribozyme cleaved at the end of $30 \mathrm{~min}$. $\left(\sigma_{\mathrm{DMF}^{0}}=180, \sigma_{\text {Well-Plate }}{ }^{0}=740, \sigma_{\mathrm{DMF}^{0}}{ }^{0.125}=480, \sigma_{\mathrm{Well}} \mathrm{Plate}^{0.125}=670, \sigma_{\mathrm{DMF}}{ }^{0.25}=280, \sigma_{\mathrm{Well}}-\right.$ Plate $^{0.25}=360, \sigma_{\mathrm{DMF}^{0.5}}=650, \sigma_{\text {Well-Plate }^{0.5}}=1110, \sigma_{\mathrm{DMF}^{0}} 0.625=540, \sigma_{\text {Well-Plate }} 0.625=1180, \sigma_{\mathrm{DMF}^{0.75}}=560, \sigma_{\text {Well-Plate }^{0.75}}=1980, \sigma_{\mathrm{DMF}}{ }^{1}=370, \sigma_{\mathrm{Well}}-$ Plate $^{1}=940$ ).

$5 \mu L$ Assay on Well-Plate

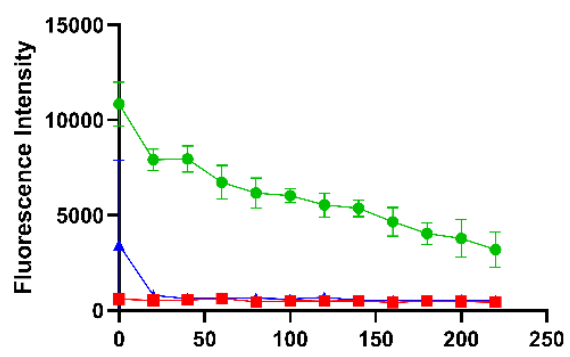

$2.5 \mu \mathrm{L}$ Assay on Well-Plate

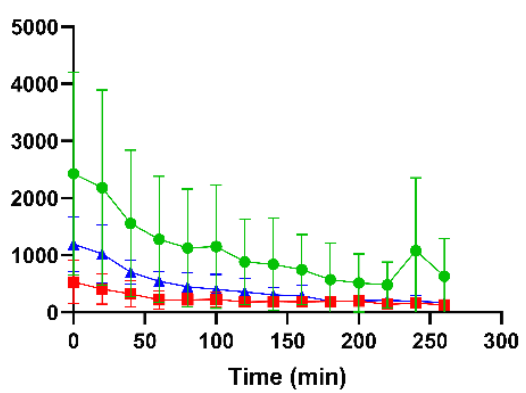

$1.5 \mu \mathrm{L}$ on Well-Plate

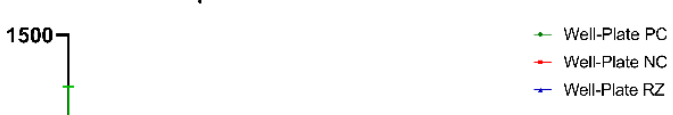

Figure S13: Ribozymatic assays on Well-Plate at lower volumes. Ribozyme cleavage assays (RZ) were carried out on a Corning 384 Well-Plate at lower volumes $(5 \mu \mathrm{L}, 2.5 \mu \mathrm{L}$, and $1.5 \mu \mathrm{L})$ with 2 controls. A strand displacement reaction served as the positive control (PS), whereas a quenched probes acted as the negative control (NC). The progress of the reactions was observed by reading the fluorescence frequently every 20 mins and plotting the readings over time. $\left(\mathrm{n}=3, \sigma_{\mathrm{PC}^{5}}=990, \sigma_{\mathrm{NC}^{5}}=80, \sigma_{\mathrm{RZ}^{5}}=40, \sigma_{\mathrm{PC}}{ }^{2.5}=400, \sigma_{\mathrm{NC}}{ }^{2.5}=\right.$ $20, \sigma_{\mathrm{RZ}}^{2.5}=70, \sigma_{\mathrm{PC}^{1}} 1.5=60, \sigma_{\mathrm{NC}^{1.5}}=90$, and $\sigma_{\mathrm{RZ}}{ }^{1.5}=60$ ). 
Table S1. Primers are generated by the tool Primerize for the assembly of the ribozyme.

\begin{tabular}{|l|l|}
\hline Primer Name & Primer Sequence \\
\hline R1 & 5' CGTCCGAAGGGTGAGAAATCGCAGAGCCTACATGTCGGACTCAT 3', \\
\hline F1 & 5' TTCTAATACGACTCACTATAGGAAATCCCTGATGAGTCCGACATGTAGGCT 3' \\
\hline R2 & 5' ACAGGGTCGGACCTGGAAATCCTACGCAGGCGTGCGTT 3' \\
\hline F2 & 5' TCTCACCTTCGGACGAAACGCACGCCTGCGTAGGATTTCCA 3' \\
\hline
\end{tabular}

Table S2. Parameters of linear regression fit to the benchtop and on-chip negative controls.

\begin{tabular}{|l|l|l|}
\hline Parameters & Well-Plate & DMF Chip \\
\hline YIntercept & $1000+-61$ & $1120+-22$ \\
\hline XIntercept & $-1840+-550$ & $-3300+-1500$ \\
\hline Slope & $0.53+-0.51$ & $0.33+-0.18$ \\
\hline
\end{tabular}

Table S3. Parameters of linear regression fit to the benchtop and on-chip positive controls.

\begin{tabular}{|l|l|l|}
\hline Parameters & Well-Plate & DMF Chip \\
\hline YIntercept & $12400+-420$ & $11900+-360$ \\
\hline XIntercept & $12500+-1580$ & $-14000+-1560$ \\
\hline Slope & $-1.0+-3.5$ & $0.85+-3.1$ \\
\hline
\end{tabular}

Table S4. Parameters of linear regression fit to the benchtop and on-chip assay.

\begin{tabular}{|l|l|l|}
\hline Parameters & Well-Plate & DMF Chip \\
\hline YIntercept & $1290+-140$ & $2010+-95$ \\
\hline XIntercept & $-120+-40$ & $-180-+40$ \\
\hline Slope & $10.30+-1.6$ & $11.2+-0.8$ \\
\hline
\end{tabular}

Table S5. Parameters of one phase decay regression fit to the benchtop and on-chip ribozyme cleavage assay.

\begin{tabular}{|l|l|l|}
\hline Parameters & Well-Plate & DMF Chip \\
\hline$Y_{0}$ & $0.00087-+0.00007$ & $0.00078+-0.00004$ \\
\hline Plateau & $0.00021+-0.00008$ & $0.00026+-0.00002$ \\
\hline K & $0.01+-0.003$ & $0.026+-0.005$ \\
\hline Half Life & $68+-18$ & $27+-5$ \\
\hline Tau & $99+-25$ & $39+-7.3$ \\
\hline
\end{tabular}


Table S6. Parameters of sigmoidal curve fit to the ribozyme cleavage assay on benchtop and on-chip experiments with different input concentrations.

\begin{tabular}{|l|l|l|}
\hline Parameters & Well-Plate & DMF Chip \\
\hline Top Plateau & $4100+-300$ & $3900+-50$ \\
\hline Bottom Plateau & $2100+-250$ & $2100+-70$ \\
\hline LogIC50 & $-0.22+-0.21$ & $-0.6482+-0.2$ \\
\hline IC50 & $0.61+-0.31$ & $0.22+-0.02$ \\
\hline
\end{tabular}

Table S7. An estimation of the cost and time of ribozymatic experiments on both well-plate and DMF chips.

\begin{tabular}{|c|c|c|c|c|}
\hline & $\begin{array}{ll}\text { Well } & \text { Plate } \\
(384) & \end{array}$ & $\begin{array}{l}\text { DMF } \\
\text { chip }\end{array}$ & $\begin{array}{l}\text { DMF } \\
\text { chip }\end{array}$ & Additional Comments \\
\hline $\begin{array}{l}\text { Final volume of reaction } \\
\text { in } \mu \mathrm{L}\end{array}$ & 10 & 2.5 & 1 & $\begin{array}{l}\text { Lowering the volume of assays in the well } \\
\text { plate resulted in inconsistent results. }\end{array}$ \\
\hline Number of controls & 2 to 6 & 2 to 6 & 2 to 6 & $\begin{array}{l}\text { The controls include: } \\
\text { - Positive control (a strand displacement } \\
\text { reaction). } \\
\text { - Negative control (quenched probe). } \\
\text { - Assay with no input/activation strand. } \\
\text { - Assay with no magnesium ions. } \\
\text { - Assay with wrong input strand. } \\
\text { - Assay with no input and magnesium strand } \\
\text { but with ribozyme. }\end{array}$ \\
\hline $\begin{array}{l}\text { Reagent costs per reaction } \\
\text { (in } \mathrm{CAD} \text { ) }\end{array}$ & 0.2 & 0.05 & 0.02 & \\
\hline $\begin{array}{l}\text { Max number of reactions } \\
\text { on the platform }\end{array}$ & 384 & 8 & 8 & $\begin{array}{l}\text { The chip used in the experiments supports the } \\
\text { analysis of a maximum of eight droplets. }\end{array}$ \\
\hline $\begin{array}{l}\text { Cost of one device (in } \\
\text { CAD) }\end{array}$ & 50 & 10 & 10 & \\
\hline
\end{tabular}




\begin{tabular}{|c|c|c|c|c|}
\hline Reusability of the device & 0 & 5 times & 2 times & $\begin{array}{l}\text { Reactions at } 1 \mu \mathrm{L} \text { involved dispensing and } \\
\text { merging two droplets of size } 0.5 \mu \mathrm{L} \text { (a } \\
\text { ribozyme containing droplet and a droplet of } \\
\text { the probe). Hence, for eight assays, } 16 \text { droplets } \\
\text { were moved across the chip. These droplets } \\
\text { shared the same paths and left traces on the } \\
\text { electrodes. This resulted in biofouling and } \\
\text { sometimes caused the chip to burn, thereby } \\
\text { reducing the chip's reusability. } \\
\text { Whereas at } 2.5 \mu \mathrm{L} \text {, a droplet }(0.5 \mu \mathrm{L}) \text { of } \\
\text { ribozyme was merged with an already pipetted } \\
\text { droplet }(2 \mu \mathrm{L}) \text { of the probe. This limited the } \\
\text { number of moving droplets on the device, } \\
\text { increasing the chip's reusability. }\end{array}$ \\
\hline $\begin{array}{l}\text { Number of devices required to monitor } \\
384 \text { assays }\end{array}$ & 1 & 10 & 24 & $\begin{array}{l}\text { On a single } 384 \text { well-plate we can analyze } 384 \\
\text { different reactions. Therefore, the number of } \\
\text { DMF devices required for the same number of } \\
\text { analysis was determined after considering the } \\
\text { chip reusability. }\end{array}$ \\
\hline $\begin{array}{l}\text { Approximate } \\
\text { reagent } \\
\text { costs for } 384 \text { experiments (in CAD) }\end{array}$ & 150 & 37 & 15 & \\
\hline $\begin{array}{l}\text { Approximate device costs } \\
\text { for } 384 \text { experiments (in } \\
\text { CAD) }\end{array}$ & 50 & 100 & 240 & \\
\hline $\begin{array}{l}\text { Cost of all materials for } 384 \text { experiments (in } \\
\text { CAD) }\end{array}$ & 200 & 137 & 255 & \\
\hline Cost of all materials for 1 Experiment (in CAD) & 0.52 & 0.35 & 0.66 & \\
\hline Per hour labour cost (in CAD) & 15 & 15 & 15 & \\
\hline Time required for device Fabrication (in hrs) & 0 & 6 & 6 & $\begin{array}{l}\text { The chips were designed and later fabricated } \\
\text { in wet labs. }\end{array}$ \\
\hline $\begin{array}{l}\text { Time required to perform one experimentation } \\
\text { (in hrs) }\end{array}$ & 0.5 & 0.5 & 0.5 & \\
\hline $\begin{array}{l}\text { Total expenses to perform one experiments (in } \\
\text { CAD) }\end{array}$ & 8.02 & 97.85 & 98.16 & $\begin{array}{l}\text { Fabrication of one chip and } 12 \text { chips would } \\
\text { require the same amount of labour and time. } \\
\text { This makes the experiments on the DMF chip } \\
\text { expensive. }\end{array}$ \\
\hline $\begin{array}{l}\text { Total expenses to perform one experiments } \\
\text { using an already fabricated device (in CAD) }\end{array}$ & 8.02 & 7.85 & 8.16 & $\begin{array}{l}\text { Assumption: } \\
\text { - The DMF chips used in the experiments are } \\
\text { already fabricated. }\end{array}$ \\
\hline
\end{tabular}

